\title{
Moulin Rouge (1952 y 2001): dos estilos de dirección artística
}

\section{RESUMEN}

Este artículo analiza a dirección artística de dúas películas homónimas tituladas Moulin Rouge rodadas en etapas históricas distantes cronolóxicamente: 1952 e 2001, feito que se reflicte nos respectivos estilos de dirección artística. Partindo da conceptualización do termo dirección artística, efectuaremos un análisis temático, estilístico y expresivo dos principais rasgos do vestiario e escenografía de ambos filmes. Con este fin, analizaremos as similitudes e diferencias da representación da sociedade, da cidade de París, do cabaret Moulin Rouge asi como do contexto histórico que retratan ambas películas.

\section{PALAVRAS-CHAVE}

dirección artística

Moulin Rouge

moda

\section{ABSTRACT}

This article looks at artistic direction duas homonymous film entitled Moulin Rouge-filmed in chronologically distant historical periods: 1952 and 2001, which reflects in different styles of artistic direction. From the conceptualization of the artistic direction, we undertook a thematic analysis, of stylistic and expressive features, the wardrobe and scenery of both films. To this end, we discuss similarities and differences as representing society, the city of Paris, Moulin Rouge cabaret as well as the historical context that both films portray.

\section{KEY WORDS}

artistic direction

Moulin Rouge

fashion
La dirección de arte, según Félix Murcia es una de las especialidades no específicas del cine (MÚRCIA, 2002, p. 45). Siguiendo a Marcel Martin, lo son también la iluminación, decoración, vestuario, color, interpretación, la pantalla grande y Murcia añade además la música. Su principal cometido es lograr la verosimilitud de los escenarios y se sirve para ello de la "escenotecnia" como recurso tanto técnico como artístico. Debe dotar a estos escenarios, ya sean naturales (paisajes), artificiales preexistentes (edificaciones), construidos artificialmente (decorados) o adaptados (paisajes y edificaciones reales y decorados artificiales) tanto de funcionalidad como de expresividad, desde las exigencias que plantea cualquier acción dramática que se pretenda filmar. Independientemente, los decorados poseen también, por sí mismos, su propia expresividad para sugerir ambientes o realzar ideas.

Sintetizando, Murcia afirma que la dirección de arte es la plasmación del proyecto plástico de una película, es decir, la escenografía, las pautas del vestuario, y en definitiva, todo lo que se ve físicamente en la película. En resumen, la trascendencia de la dirección de arte se debe a que se trata de un arte destinado a la obtención de espacios concretos necesarios para desarrollar en las películas una determinada acción dramática propuesta desde un guión, de forma que ésta pueda ser filmada desde la particular visión de un director de cine. Así puede resumirse sencillamente la dirección de arte, sin retórica alguna, aunque se sabe que para lograr este fin ha de servirse de recursos artificiales y también naturales que proporcionen la necesaria verosimilitud o credibilidad a los escenarios de cualquier ficción. Para lograrlo, aplica técnicas industriales especializadas y tratamientos artísticos a cuyo conjunto se denomina "escenotecnia".

Sin embargo, los escenarios no tienen expresividad propia por su estilo artístico, construcción arquitectónica, policromía ornamental o atrezzo deslumbrante. La obligación de contribuir a dar consistencia al espectáculo, por un lado, y la necesidad de que éste sea disfrutado por el público universal, por otro, hacen que la dirección de arte tenga que servir, en cualquier tipo de película, de otros medios más domésticos o populares para transmitir con viveza tanto información como ideas capaces de influir en el ánimo del espectador de cualquier nivel cultural.

En las películas analizadas, las dos versiones de Moulin Rouge distantes 48 años entre sí, encontramos con escenarios diseñados con aparente naturalidad en la versión de John Huston frente al exhibicionismo inherente a las producciones de Baz Luhrmann.

El trabajo del director de arte se centra en la preparación del rodaje ya que es una labor previa a la 
de los equipos supeditados a la filmación. Partiendo del guión técnico o literario, se buscan y establecen localizaciones, ambientación, vestuario y escenografía con la correspondiente repercusión que estas decisiones tienen en los departamentos de vestuario, peluquería, fotografía, dirección, producción. En ocasiones, este trabajo pasa inadvertido sin embargo en otras se convierte en el personaje principal del producto, donde la espectacularidad de la puesta en escena es su mayor atractivo. La dirección de arte se aprecia especialmente en aquellos géneros que hacen más evidente para el público toda esta labor: histórico, musical, ciencia-ficción, etc.

\section{Dos visiones de Moulin Rouge}

Aunque muy distantes en su hilo argumental, la comparación entre las dos películas sigue siendo válida. Al margen de los aspectos formales y estéticos, estas dos versiones de Moulin Rouge muestran diferencias en el género. La primera versión constituye claramente una biografía de Toulouse Lautrec e incide en el aspecto sórdido y decadente de la época mientras que la versión de Baz Luhrmann, el amor es el protagonista principal de este musical que relata el romance de un poeta con la estrella del cabaret.

La historia de ambas películas nos sitúa en la vida bohemia de Montmartre, a principios de siglo con la ebullición de los ismos, representados en la figura de Toulouse-Lautrec, con toda la pasión por el arte y el espectáculo que se da cita en el mítico cabaret del Moulin Rouge. Mientras que el film de John Huston se centra exclusivamente en la figura del citado pintor, Baz Luhrmann reinterpreta la novela de Pierre La Mure adaptándola al formato del musical y cediendo el protagonismo a un poeta que llega al famoso local para realizar una obra romántica.

\section{Moulin Rouge (1952)}

En relación con la escenificación, hay extraordinarias similitudes entre el aspecto visual de la película y el arte de Toulouse-Lautrec cuyas pinturas se parecen al mundo de la película (en lo que se refiere al color, la composición, la escala, la iluminación). La secuencia de créditos inicial de la película con el estilo tipográfico de un cartel de Toulouse-Lautrec es una muestra de que éste será el estilo plástico que presidirá el film.

Además, la producción de Moulin Rouge simbolizó de muchas formas la nueva relación de Hollywood con Europa y el resto del mundo tras la Segunda Guerra Mundial. La película se financió con dinero británico, que le dio a Huston más poder sobre la producción mientras permitía a los inversores británicos conseguir el acceso al mercado americano que, de otra forma, sería inalcanzable.

\section{Moulin Rouge (2001)}

Ante todo, se intentó recrear con la máxima fidelidad posible el mundo del Moulin Rouge. No obstante, es obvio que el director se permite una serie de licencias artísticas tanto en fotografía como en vestuario, maquillaje y peluquería más bien pertenecientes al siglo XIX que de comienzos de siglo.

La imaginería de la película fusiona dos tendencias separadas por un siglo en una estética sorprendente. En este filme, predominan juegos de luces, humo, proyecciones y maquetas. La cámara, que realiza movimientos cuasi acrobáticos, no oculta que estamos en un gran estudio de filmación donde se puede observar la escenografía de frente, de lado, por encima $\mathrm{y}$ entre bastidores.

Con esta película queda claro que el musical, es el único género capaz de emplear de modo natural la estilización porque en él todo es imaginación, irrealidad y teatralidad sublimada.

\section{Dos sociedades coetáneas: belle époque y bohemia}

A finales del siglo XIX, nació en París una época bautizada como la Belle Époque. Tal y como su nombre sugiere, esta Belle Époque se caracterizó por la prosperidad, la libertad empresarial y sobre todo, social.

La Belle Époque dio lugar a una nueva cultura que comprendía un estilo de vida definible como moderno. Con la intención de conmemorar el centenario de la Revolución Francesa, una revolución contra el privilegio y la injusticia, París organizó la Exposición Universal de 1889. De tal modo, se pusieron al servicio tanto del trabajador como del burgués una gran variedad de entretenimientos y nuevas tecnologías. Esta igualdad a la hora de disfrutar de ciertos placeres marcó una democratización del ocio que ya anunciaba el nacimiento de la cultura de masas que culminaría en el siglo XX.

La automatización de los procesos y la fabricación en serie conllevó recompensas embriagadoras. Había mayor cantidad de pan, vino, libros, textil, objetos de moda y nuevos conceptos de almacenes en los que comprarlos. La población empezó a enamorarse de las nuevas tecnologías que surgieron por entonces: la invención del telégrafo, el teléfono, el elevador, la bicicleta, las cámaras hechas a mano, los primeros coches, la luz eléctrica y las máquinas de escribir, además de avances tanto en la higiene pública como en la cirugía. Todo ello conformó un estado de optimismo al mismo tiempo práctico y utópico.

Se trataba de un momento histórico fundamentalmente dominado por la riqueza y la belleza, que también tenía que convivir con la pobreza, pobreza que trajo consigo la Bohemia y con ella, numerosos males sociales (al margen de las grandes obras artísticas). Para los bohemios que residían en Montmartre, la promesa de "la Verdad, la Belleza, la Libertad y el Amor" en un mejor mundo, parecía germinar en ese momento histórico precisamente con 
la aparición de las citadas nuevas tecnologías por entonces sin precedentes.

Al margen del progreso y el optimismo, las ventajas de la época de la máquina también trajeron consigo amargos dilemas sociales. Hasta entonces, los habitantes de París nunca habían consumido tanto alcohol, engendrando una nueva enfermedad social: alcoholismo. La tuberculosis, la prostitución organizada, la extensión de sífilis, y la promesa de ingresos regulares llevó a que muchos miembros pertenecientes a colectividades rurales emigrasen a las ciudades.

\section{Para los bohemios que residían} en Montmartre, la promesa de "Ia Verdad, la Belleza, la Libertad y el Amor" en un mejor mundo, parecía germinar en ese momento histórico precisamente con la aparición de las citadas nuevas tecnologías por entonces sin
precedentes

Apareció entonces el nuevo concepto de "horas de ocio" y con él, una mayor demanda de entretenimiento para las masas. Así, la incipiente clase media encontró más tiempo para la distracción - y puesto que había más dinero para gastarlo con lo que se produjo una demanda creciente de la entretenimiento popular, de pistas de carreras, circos, ópera, burdeles, cabarets.

Culturalmente, se trata de una época y un lugar que empezaba a rebelarse contra el artificio del romanticismo para enfrentar el nuevo siglo XX con el naturalismo de Zola, con Toulouse-Lautrec y otras tendencias que por entonces eran calificadas como revolucionarias.

En definitiva, este París de la Belle Époque dominado por la high-life - locución inventada por los visitantes ingleses de 1900 en París - fue deslizándose hacia una permisividad moral en todas las vertientes: las drogas aparecieron en sus formas antiguas de morfina y cocaína; el cuerpo fue haciéndose protagonista del vestido; el sexo y sus aditamientos se convirtieron en fetiches eróticos de la moda. Se hicieron presentes gigolós y gigolettes y la exaltación del maquereau llenaba los escenarios del teatro de varieté.

En este sentido, 1900 es el comienzo de un capítulo de la historia de París que rebosa escepticismo profundo pero acepta los valores que se ofrecen aún a sabiendas de que son falsos. Hay como un vértigo de parecer avanzados, de vivir peligrosamente con desgarro moral.

\section{La sociedad en Moulin Rouge (1952)}

En este film aparecen retratados desde los prostíbulos y los personajes que los habitaban hasta la Belle Époque. A continuación, retrataremos la sociedad que aparece en esta versión de Moulin Rouge a través del análisis de sus personajes:

La Goulue: Apodo de Louis Weber (1870-1929). El film retrata la caída del éxito hasta la más absoluta decadencia de esta bailarina y actriz. En el Moulin Rouge llegó a ser la máxima atracción hasta 1895. Los periódicos de la época y los carteles de ToulouseLautrec aureolaron su nombre. Posteriormente, se inició el declive de la cuadrilla y con él el de la Goulue. En 1895 instaló una barraca en en la Foire du Trône decorada por Toulouse y llevó a cabo algunas actuaciones en el Jardín de París. Su vida se plasma en el film desde el inicio en el que contaba con gran éxito en sus actuaciones hasta su declive representado cuando Toulouse la encuentra ebria y visiblemente desmejorada rodeada de vagabundos.

Valentin-le-Dèsossé: Su nombre real era Edme Etienne Renaudin. Actuó como primer bailarín en el Tivoli Vauxhall y también como director de danza entre otros en el Moulin Rouge. Llama notablemente la atención su aspecto físico presidido por una gran nariz aguileña, que aparece representada en un conocido cartel de Toulouse-Lautrec.

Jane Avril: Bailarina, cantante y actriz (París, 18681943). En 1890, bajo el seudónimo de "Mélinite" bailó en la "cuadrilla naturalista" del Moulin Rouge. Entre 1890 y 1894 alcanzó grandes éxitos en El jardín de París y el Folies Bergère. Después actuó como actriz en el Peer Gynt de Ibsen y en Claudine à París de Colette; en 1897 bailó en el Casino de París. Tras sus intervenciones como patinadora en el Palais de Glace actuó en Londres en el Palace Theatre con la compañía de la Eglantines. Ya en el nuevo siglo siguió cosechando éxitos, incluso en Estados Unidos para volver por último al Moulin Rouge. Finalmente, carente de medios, fue acogida por institución para ancianos donde vivió hasta su muerte.

Su distinción contrastaba con la ordinariez de la Gouloue. Su talento artístico no sólo se demostraba en la coreografía y en la danza, sino también en el hecho de que ella misma confeccionaba su vestuario.

Todos ellos pasaron a formar parte de la historia del arte gracias a Toulouse-Lautrec, quien les regaló la inmortalidad en sus obras.

Contamos con dos ejemplos más de las clases sociales extremas de la época representadas en las figuras de la prostituta Marie y la aristócrata Myriamme. Sus figuras representan contactos amorosos que marcarán de forma definitiva al protagonista Toulouse-Lautrec 
y no están inspirados en personajes que el pintor retratase en sus carteles:

Marie: Prostituta que pertenece a una clase social mísera de la sociedad de la época.

Myriamme: Representa todo lo contrario que Marie y aparece como una mujer aristócrata, independiente, inteligente y culta cuya distinción choca frontalmente con la vulgaridad del anterior personaje.

\section{La sociedad en Moulin Rouge (2001)}

En el film de Luhrmann aparecen representadas desde la clase social más alta personificada en la figura del Duque de Monroth hasta los estratos más bajos con una existencia más miserable como son las prostitutas o los bohemios. Baz Luhrmann retrata esa sociedad bohemia decadente en la que podemos destacar los siguientes personajes:

Christian, un joven poeta que busca a los bohemios de Montmartre en París, que abrazan ideales como la Belleza, la Verdad, la Libertad y por encima de todo, el Amor.

Satine, chica de alterne, bailarina y la estrella del mítico Moulin Rouge. Una verdadera heroína trágica que hace de la fuerza su máscara.

Zidler se puede definir como un oportunista del submundo, figura paterna y proxeneta de Satine. En realidad, es un hombre de negocios dedicado al espectáculo. Por ello, hará todo lo que pueda para ver el Moulin Rouge convertido en un teatro, incluyendo convencer a Satine para que induzca al Duque a financiar la operación.

El Duque de Monroth es un ejemplo de represión, producto de una rígida sociedad inglesa. Su riqueza le convierte en un objetivo para Zidler quien utiliza a Satine para engañarlo con el propósito de financiar el próximo espectáculo del Moulin Rouge.

Los bohemios están representados por los llamados "chicos de la revolución" que se basan de forma aproximada en personajes históricos reales, tomándolos únicamente como punto de referencia. Juntos están intentando estrenar en el Moulin Rouge el primer espectáculo musical del mundo totalmente bohemio "Espectacular, espectacular". Entre ellos, podemos citar a: Toulouse-Lautrec, el Doctor, un inventor y Satie, un excéntrico genio musical y experimentador electrónico.

También aparecen retratadas las prostitutas más conocidas del cabaret denominadas como "cuatro jinetes del Apocalipsis".

\section{El cabaret Moulin Rouge y su contexto histórico}

Areilza afirma que en esta Belle Époque, la burguesía ascendía en poder económico y la guerra europea no era más que una amenaza lejana (1989, p. 79-80). París, desde la Exposición Universal, se convirtió en un centro de atracción mundo al cual las clases sociales altas de los países europeos y americanos acudían.
Las denominadas "revistas", como género del espectáculo nocturno, fueron abriéndose camino poco a poco, en la última mitad del siglo XIX, como evolución de los antiguos cafés-cantantes y de los posteriores cafés-concierto. Y finalmente, como tantas otras costumbres sociales, desde Londres llegó a París la exitosa fórmula del music-hall conocida popularmente como cabaret.

Literalmente, el cabaret es el espectáculo de variedades que combina diversos números independientes, con presencia importante del componente erótico, representado en un local de reducidas dimensiones que permite un contacto muy directo entre el público y el artista. Números habituales en los espectáculos de cabaret son los de magia, baile moderno, strip-tease y humor. Se denomina cabaret también al local en donde tienen lugar este tipo de espectáculos y donde el espectador se halla sentado en mesas independientes y dispone de un servicio de bar $\mathrm{y}$ a veces de restaurante.

Así, del desde el Alhambra - así se denominaba al famoso music-hall británico - pasó a París, donde recibió el nombre de Folies Bergère, situado en la Rue Richer. El éxito obtenido hizo que aparecieran en rápida sucesión hasta seis music-halls en la capital francesa, entre los cuales se encontraba nuestro objeto de estudio: Folies Bergère, Moulin Rouge, Casino de París, Olimpia, Alcázar d'Eté, Ambassadeurs.

\section{El cabaret es el espectáculo de variedades que combina} diversos números independientes, con presencia importante del componente erótico, representado en un local de reducidas dimensiones que permite un contacto muy directo entre el público y el artista

Tenían en común la estructura del programa de actuación que incluía: introducción a veces circense, una serie de actuaciones individuales y una pantomima musical con ballet. De los cabarets citados, siguen en pie tres de ellos: Folies Bergère, Moulin Rouge y Casino de París, aunque con espectáculos de otra índole y adaptados a los tiempos actuales.

Aquella novedad escénica fue acogida con creciente éxito y dio lugar a un sistema de publicidad callejera 
hasta entonces inexistente: el cartel o póster cuyo máximo exponente fue Toulouse-Lautrec. Realmente, estos carteles han conseguido erigirse como símbolo de este momento histórico ya que diariamente llenaban las calles y boulevares parisinos con sus notas de litografía coloreada.

El music-hall era entonces no sólo un escenario de exhibición de arte y danza, sino un lugar de reunión y galanteo en que una parte del público se acercaba y conversaba con las protagonistas del espectáculo en los promenoirs inmensos que tenían cabida para muchos cientos de espectadores. Se iba al music-hall a contemplar y aplaudir, pero también a conocer y trabar contactos con las vedettes de moda - que eran como estrellas de rock actuales - el cual era uno de los mayores alicientes.

El Moulin Rouge, sala de espectáculos parisina, que en sus inicios fue un café concierto, después un musichall, antes de convertirse en uno de los raros vestigios de la Belle Époque en la capital francesa.

Por iniciativa de Charles Zidler y Joseph Oller, construyeron un local de baile y uno de los grandes lugares de esparcimiento de la vida parisina, en el cual se celebraban conciertos y atracciones de diferentes estilos. El principal factor que contribuyó al aumento de su reputación fue la célebre danza francesa, derivada de la cuadrilla, conocida como cancán. Bailarinas, como la Goulue (la Glotona), Grille d'Egout (Rejilla de Alcantarilla), la Môme Frommage (la Momia Queso), Rayon d'Or (Rayo de Oro) y Nini Pattes-en-l'Air (Nini Patas al Aire), y otros artistas, como Valentin le Desossé (Valentín el Deshuesado), acróbata y contorsionista, le Pétomane o Jane Avril marcaron la gran época del Moulin Rouge.

En 1900 un nuevo director reemplazó la sala de baile por un gran teatro concierto - parte histórica que se refleja en el film de 2001 - en el que se presentaron varios espectáculos de revista de gran magnitud. En 1915, después de un periodo de dificultades económicas y varias quiebras, el local fue arrasado por las llamas en un incendio. Reconstruido en 1922, Jacques-Charles lo transformó en uno de los más célebres music-halls del mundo gracias a la presencia de estrellas como Mistinguett, Joséphine Baker, Jeanne Aubert o Maurice Chevalier. Más tarde fue transformado, bajo los auspicios de Pierre Foucret, en cine y cabaret.

Así, el Moulin Rouge ascendió muy pronto a la categoría de cabaret preferido de Montmartre, lo que podría explicarse por las presentaciones de sus estrellas y por la originalidad y magnificencia de su decoración. El molino rojo que se conserva actualmente, surgió de un diseño concebido como imitación de los numerosos molinos de viento verdaderos que hubiera alguna vez en Montmartre que antes de ser un barrio fue una localidad característica por aquellos molinos en que se molía harina y que más tarde se convertirían en locales de diversión muy populares.
Estructuralmente, el Moulin Rouge original constaba de las siguientes partes: la fachada presidida por el famoso Molino Rojo; una gran pista de baile central formada por varios desniveles en donde se llevaban a cabo las presentaciones de las estrellas. A su alrededor, se situaba un promenoir con numerosas mesas, unas de ellas siempre reservada para Toulouse-Lautrec, de la cual hacía uso casi cada noche y también varios saloncitos; en el jardín del Moulin Rouge se hallaba un elefante gigante adquirido el año de la inauguración del local en la Feria Internacional de París. En su interior alojaba un pequeño club de tema árabe donde, mientras uno tomaba sustancias alucinógenas ya que era un fumadero de opio, era agasajado con la danza del vientre. El interior del animal se usaba para exponer "curiosidades" y a la entrada, en terciopelo rojo, se encontraba el cuadro de Toulouse-Lautrec "Amazona en el circo Fernando".

En la película de John Huston no se contempla esa división estructural del Moulin Rouge y tan sólo presenta al espectador la fachada con el Molino Rojo para inmediatamente permitirle el acceso a la sala de baile donde los músicos interpretan desde su palco y las bailarinas ejecutan sus danzas de cancán.

Dado la posibilidad de rodar en los propios escenarios naturales de la ciudad de París, la película no está tan centrada exclusivamente en el cabaret y al incluirse otros exteriores naturales, se prescinde de detalles como el elefante que presidía el jardín del Moulin Rouge.

El Moulin Rouge, sala de espectáculos parisina, que en sus inicios fue un café concierto, después un music-hall, antes de convertirse en uno de los raros vestigios de la Belle Époque en la capital francesa

Otros sets de exteriores naturales en los que se rodó fueron: el Castillo de Malromé donde Toulouse pasó su infancia y fallecería, el Hipódromo y uno de los puentes sobre el Sena.

En el film de 2001 sí se distinguen perfectamente las tres partes que constituían el Moulin Rouge. A continuación, podemos observar las diferencias entre el Moulin Rouge real y el recreado para el film: Fachada y jardín con elefante hindú..

El elefante que aparece en el film es una estatua del dios hindú con cabeza de elefante Ganesh. Los interiores 
del elefante son de una riqueza visual impresionante potenciada por el detallado atrezzo de objetos exóticos. Las telas empleadas procedían directamente de la India a donde Brigitte Broch se dirigió personalmente y ordenó hacer todos los bordados plateados y dorados y telas de terciopelo.

Los sets construidos son tan detallados que nos permiten observar tanto los camerinos y partes normalmente invisibles del teatro, así como la gran representación del show final que destaca por su magnificencia.

Inspirándose en la realidad, se le añaden dos sets completamente diferentes que destacan por manifestar a la perfección la personalidad de los individuos que los habitan: el ático en el que vive el protagonista se sitúa justo enfrente de la fachada del Moulin Rouge y refleja los distintos estados de ánimo del poeta Christian. La palabra Lamour sobre él dice mucho del romanticismo del que habita en su interior. Mientras tanto el castillo gótico, situado en uno de los laterales del Moulin Rouge, que existió en realidad. A partir de él, se creó la leyenda de este Conde oscuro, reprimido, capaz de llegar a matar para conseguir lo que anhelaba.

\section{Representación de la ciudad de París}

John Huston alternó el rodaje entre escenarios naturales del auténtico París (así, vemos las calles de París, los puentes, el río Sena) y escenarios artificiales de interior. Según afirmaba John Huston por entonces "hoy en día [se trataba del año 1986] es prácticamente imposible rodar en París, pero en aquellos días las autoridades fueron muy amables. Colaboraron hasta el punto de cerrar el paso a una extensión de más de un kilómetro cuadrado delante del Deux Magots, en la orilla izquierda del Sena, durante toda la tarde de un sábado, para que pudiésemos reproducir de modo realista el ambiente de la Belle Époque" (Huston, 1986, p. 256).

Mientras tanto, la totalidad del film de Baz Luhrmann fue rodada en interiores artificiales en los Estudios Fox en la ciudad de Sydney (Australia). En ningún momento, aparecen escenarios naturales de la ciudad de París, la ciudad tan sólo aparece retratada mediante el uso de maquetas tanto en las imágenes aéreas de la misma como en aquellas imágenes en las que los protagonistas pasean sobre los tejados de París hasta llegar incluso a subirse a la Torre Eifffel.

\section{Diferencias en el diseño de vestuario}

El vestuario ideado para la versión de 1952 es más acorde con la época que el de la película de 2001. Así, los caballeros visten como dandis y las vedettes como auténticas estrellas.

Toulouse-Lautrec como protagonista aparece la mayor parte de las ocasiones con traje oscuro, camisa y sombrero excepto cuando se encuentra en su atelier que viste una ropa apta para sus trabajos pictóricos. Cuando la ocasión lo requiere, también lleva complementos tales como la chistera, bufanda y guantes blancos; así como un bastón.

El vestuario de Jane Avril en su condición de estrella de cabaret presenta una gran riqueza de tejidos de gran variedad, al igual que los vestidos de Myriam acordes con su condición de miembro de la alta burguesía. Presentan abundantes complementos como sombreros con plumas siempre caracterizados por un colorido muy vivo.

En cuanto a la versión de 2001, el vestuario de la protagonista Satine destaca por su espectacularidad y casi siempre presenta incrustaciones de diamantes, símbolo de que ella es el sparkling diamond. Gran parte de la película presenta toques de exotismo que en sentido estricto, no puede considerarse simplemente como un tomar prestado un traje extranjero, pues no se trata de una copia sino de una asimilación; es un juego de cultura. En el número final de la actuación, los materiales de base utilizados para la confección de los trajes denotan una extraordinaria variedad que mezcla el drapeado y el cosido.

El vestuario de Christian, al contrario, en consonancia con su condición de poeta arruinado se caracteriza por su sobriedad (casi siempre, camisa blanca, chaleco y pantalón negro, chaleco) excepto en las ocasiones en que luce frac, con chistera y pajarita.

Los vestidos de las bailarinas de cancán destacan por su riqueza de colorido y de tejidos. Debido a la agresividad de sus movimientos permiten ver las ligas y medias de las artistas que no llevaban las mencionadas enaguas-pantalón. Su danza de cancán es planteada como una lucha violenta entre bandas rivales por lo que el vestuario se adapta a dicha circunstancia.

Entre los extras que aparecen en el film, encontramos numerosos vestidos inspirados en el universo circense: payasos, arlequines, siamesas...

Cabe destacar los espectaculares vestidos empleados en la representación final inspirados en el mundo hindú que destacan por la riqueza de los complementos (joyas y múltiples adornos sobre los trajes) y la espectacularidad de sus telas.

\section{Conclusiones}

Tras realizar el análisis temático, estilístico y expresivo de la dirección artística de dos filmes con el mismo título, inspirados en el mismo local y momento histórico, podemos observar que las diferencias entre ambos son considerables.

Mientras la película de John Huston intenta ser más fiel a la realidad, dando cabida a la libertad creadora (al añadir personajes imaginarios que representaban los amores del pintor) pero sin tomarse licencias 
artísticas como en el film más actual.

En cada uno de los apartados podemos comprobar las diferencias principales entre ambos films:

Comenzando por sus respectivos argumentos, mientras la versión de 1952 es una biografía que bebe de la novela homónima; la versión de 2001 se inspira libremente anulando el protagonismo de ToulouseLautrec.

La ciudad de París es planteada de modo opuesto en ambos films: Huston trata de reflejar los contradictorios ambientes existentes en la época (Belle Époque frente a la Bohemia). Mientras tanto, a Luhrmann sólo se centra en reflejar la faceta de París como "villa del pecado".

Sus visiones del cabaret Moulin Rouge son asimismo totalmente diferentes: mientras en la película de Luhrmann, monopoliza el film, en el film de Huston es más bien un pretexto para introducir la obra pictórica del artista.

Toulouse Lautrec representa a dos personajes con caracteres totalmente dispares: trágico y amargado en uno, frente a alegre y dicharachero en otro; aunque siempre alcohólico.

Y por último, la moda y complementos presentados en ambos filmes distan bastante igualmente: según la documentación existente al respecto, mientras que en 1952 el vestuario se aproxima a la realidad de inicios del siglo XX, la indumentaria de la versión de 2001 parece más bien corresponder al siglo XXI.

Por tanto, tras esta profundización en el mundo del Moulin Rouge y del París de finales de siglo, observamos que las aproximaciones al tema desde el punto de vista de la dirección artística en ambas películas son muy personales: por una parte, la película de 1952 está muy próxima a la reproducción fidedigna de la época mientras que la versión de 2001, toma la realidad como punto de partida y la trata de modo inimaginable tomándose múltiples licencias artísticas $\square$ FAMEcos

\section{REFERÊNCIAS}

AREILZA, Jose Maria de. París de la Belle époque. Barcelona: Planeta, 1989.

Gran diccionario Laroussse Francés-Español, EspañolFrancés. Barcelona: Spes Editorial, 2003.

HUSTON, John. A libro abierto. Madrid: Espasa Calpe, 1986.

LÁZARO, Rosa Maria; JAGGI, Matthias; MATTEY, Miguel, GARCÍA, Sérgio. La documentación en la dirección artística: Entrevista a Félix Murcia. Cuadernos de documentación multimedia. http://www.ucm.es/info/multidoc/revista/ cuad6-7/anexo/direccion_artistica
MURCIA, Félix. La escenografía en el cine. El arte de la apariencia. Madrid: Fundación Autor, 2002.

OLSON, Robert L. Art Direction for film and video. Boston: Focal Press, 1999.

RIVIÈRE, Margarita. Diccionario de la moda. Los estilos del siglo XX. Barcelona: Grijalbo, 1996.

RIZZO, Michael. Manual de dirección artística cinematográfica. Barcelona: Ediciones Omega, 2007.

RUHBERG, Karl; SCHNECKENBURGER, Manfred; HONNEF, Klaus. Arte del siglo XX. Köln: Taschen, 2001.

VV.AA. El Arte del Siglo XX: 1900 - 1919. Navarra: Salvat Editores, 1988.

VV.AA. Enciclopedia del Saber. España: Ediciones Castell, 1989.

VV.AA. Enciclopedia Universal Ilustrada Europeo Americana. Madrid: Espasa- Calpe, 2003.

VV.AA. Historia Universal del Arte. Barcelona: Editorial Planeta, 1987.

VV.AA. La obra completa de Toulouse-Lautrec. Los maestros de la pintura. Barcelona: Editorial Origen, 1989.

LÓPEZ TALAVERA, M. y MORAL RONCAL, A. M. Genios y atormentados: imagen del artista contemporáneo en el cine. 